\title{
(อ) OPEN ACCESS \\ Primary palliative care for older people in three European countries: a mortality follow-back quality study
}

\author{
Kim de Nooijer (D) , ${ }^{1}$ Lara Pivodic, ${ }^{1}$ Luc Deliens, ${ }^{1,2}$ Guido Miccinesi, ${ }^{3}$ \\ Tomas Vega Alonso, ${ }^{4}$ Sarah Moreels, ${ }^{5}$ Lieve Van den Block ${ }^{1}$
}

\begin{abstract}
Background Many older people with serious chronic illnesses experience complex health problems for which palliative care is indicated. We aimed to examine the quality of primary palliative care for people aged 65-84 years and those 85 years and older who died non-suddenly in three European countries.
\end{abstract}

Methods This is a nationwide representative mortality follow-back study. General practitioners (GPs) belonging to epidemiological surveillance networks in Belgium (BE), Italy (IT) and Spain (ES) (2013-2015) registered weekly all deaths in their practices. We included deaths of people aged 65 and excluded sudden deaths judged by GPs. We applied a validated set of quality indicators.

Results GPs registered 3496 deaths, of which 2329 were non-sudden (1126 aged 65-84, 1203 aged 85+). GPs in BE (reference category) reported higher scores than IT across almost all indicators. Differences with ES were not consistent. The score in BE particularly differed from IT on GP-patient communication (aged 6584: $61 \%$ in BE vs $20 \%$ in IT (OR=0.12, $95 \% \mathrm{Cl}$ 0.07 to 0.20 ) aged $85+: 47 \%$ in BE vs $9 \%$ in IT $(\mathrm{OR}=0.09,95 \% \mathrm{Cl} 0.05$ to 0.16$))$. Between $\mathrm{BE}$ and $\mathrm{ES}$, we identified a large difference in involvement of palliative care services (aged 6584: $62 \%$ in $\mathrm{BE}$ vs $89 \%$ in $\mathrm{ES}(\mathrm{OR}=4.81,95 \% \mathrm{Cl}$ 2.41 to 9.61 ) aged $85+: 61 \%$ in BE vs $77 \%$ in $E S$ (OR=3.1, 95\% Cl 1.71 to 5.53$)$ ).

Conclusions Considerable country differences were identified in the quality of primary palliative care for older people. The data suggest room for improvement across all countries, particularly regarding pain measurement, GP-patient communication and multidisciplinary meetings.

(C) Author(s) (or their employer(s)) 2020. Re-use permitted under CC BY-NC. No commercial re-use. See rights and permissions. Published by BMJ.

To cite: de Nooijer K,

Pivodic L, Deliens L, et al. BMJ Supportive \& Palliative Care 2020;10:462-468. is the simultaneous presence of multiple chronic conditions. ${ }^{3}$ The end of life of older people is thus often characterised by complex health problems, symptoms and disabilities that require palliative care. ${ }^{4}$ According to the $\mathrm{WHO}$, palliative care aims to improve the quality of life of patients with a life-threatening disease. ${ }^{5}$ Yet, concerns have been raised about the access to palliative care for older people, especially in primary care, as most approaching the end of life wish to be cared for and to die in their usual place of care. ${ }^{6-8}$ Evidence shows that older people who are dying from serious chronic conditions may be receiving poor endof-life care, such as poor communication regarding wishes and preferences for care and care planning. ${ }^{14-13}$ Similarly, access to palliative care and symptom control is increasingly problematic in old age. ${ }^{10}$

Despite these concerns, there is insufficient population-based data to assess the quality of palliative care for older people dying from serious chronic conditions and to determine whether there are specific patient groups or care domains where improvements in quality can be made. In particular, there are few crossnational studies that permit comparison of the quality of palliative care in different healthcare systems. This precludes evidence-informed policy-making to ensure high-quality palliative care for older people. Existing population-based studies assessing the quality of palliative care for older people focus on the last week of life only ${ }^{14}$ or are limited to a particular diagnosis such as cancer ${ }^{14}$ or dementia, ${ }^{15}$ thereby excluding large groups of older people for whom palliative care may also be relevant.

Measuring the quality of palliative care is complicated because palliative care often involves multiple healthcare professionals 
in various disciplines and healthcare settings, has a multidimensional nature and is integrated within a larger spectrum of healthcare services. ${ }^{16}{ }^{17}$ In many countries, general practitioners (GPs) have a good view of the care their patients received from them and other healthcare providers, hence our use of representative epidemiological surveillance networks based on general practice provides an important opportunity for evaluation. ${ }^{18}$

The systematic evaluation of quality can be achieved by using a core set of quality indicators defined as 'measurable items referring to the outcomes, processes, or structure of care ${ }^{19}$ judged as critical in the evaluation of the quality of palliative care. ${ }^{1620}$ The quality indicators assessed in general practice can therefore measure quality across different settings as delivered by various healthcare professionals and can be used to capture the quality of care on an aggregated, for example, national, level. ${ }^{19}$

We conducted this study in three countries, Belgium, Italy and Spain. All three countries have legislation and/or national strategies for primary palliative care provision, ${ }^{21-23}$ but there are also important differences in the way primary palliative care is organised. For instance, GPs in Spain fulfil a gatekeeping function to specialist palliative care services. ${ }^{18}$ In Belgium and Italy, GPs have a partial gatekeeping function in that their referral is required for certain specialist palliative care services (such as specialist palliative home care in Belgium) but not for others (eg, involvement of a mobile palliative care team in the hospital). ${ }^{18}$ GPs in Belgium and Italy still have an important coordinating role within healthcare, and most people in these countries have a GP whom they consult regularly. ${ }^{18}$ Furthermore, there are differences between these countries in how certain aspects of dying and palliative care are approached that may impact on the quality of primary palliative care. ${ }^{24}$ This includes, but is not limited to, communication about end-of-life, disclosure of diagnosis and prognosis and reliance on family care. ${ }^{24}$

The overall aim of this study was to answer the following research question: what is the quality of primary palliative care for people aged 65-84 years and those 85 years and above who died non-suddenly in Belgium, Italy and Spain?

\section{METHODS}

\section{Study design and procedure}

The data were collected as part of the European Sentinel General Practitioner Networks Monitoring End-of-Life Care (EURO-SENTIMELC) study, which was a cross-national mortality follow-back study that monitored end-of-life care in population-based samples of deceased people. ${ }^{18}$ The data were collected through nationwide sentinel networks of GPs. In Belgium and Spain, these are existing regional and national epidemiological surveillance networks consisting of representative samples of GP practices or community-based physicians. In Italy, a new network was formed for this study by the Italian Society of General Practitioners through a procedure similar to that in the other countries; GPs were only informed about the procedure and not about the subject of the surveillance in order to avoid over-representation of those with a particular interest in palliative care. The networks in Belgium and Italy were nationwide; in Spain we collected data only from two autonomous regions: the Valencian Community and Castile and Leon.

All deaths of patients aged 18 years or older were registered weekly by the participating GPs using a standardised registration form and classified as sudden and totally unexpected or non-sudden, a common method in palliative care research for retrospectively identifying people for whom palliative care was a realistic option. ${ }^{25} 26$ In Belgium and Spain, this was done from January 2013 to December 2014 and in Italy from June 2013 until May 2015.

\section{Setting and participants}

We included deaths of patients who were 65 years or older which were non-sudden as judged by the GP.

\section{Measurements}

The standardised registration form consisted of openended and closed-ended items. As well as assessing quality indicators, it asked about patient characteristics such as age, sex, primary cause of death, dementia diagnosis, main place of residence in the last year of life and place of death.

\section{Main outcome measure: quality indicators}

The quality indicators used in this study are based on the work of Leemans et al. ${ }^{27}$ They measured the quality of palliative care services by assessing nine important domains of palliative care (ie, physical, psychosocial, communication with patients, communication with relatives, multidisciplinary consultation, type of end-of-life care, continuity of care, support for relatives and structure of care). From that set, the EUROSENTIMELC consortium selected those applicable to primary care and reformulated them into questions suitable to be answered by GPs. The questions underwent review by primary palliative care experts from Belgium, Italy, Spain, France and the Netherlands and were then ranked; those with a score of at least 7.5 (scale 1-10) remained, ensuring that there was at least one question per domain of quality indicators of palliative care. The quality indicators were selected through a multistep process which can be found elsewhere. ${ }^{1528}$ The final core set consisted of nine quality indicators, of which two (3.1 and 4) cover the third palliative care domain:

1: Percentage of patients whose pain was known by the GP to be monitored regularly during the last 3 months of life. 
2: Percentage of patients known by the GP to have accepted that they were nearing the end of life.

3.1 and 4: Extent to which patients and relatives receive information from the GP about diagnosis, prognosis, disease progression, advantages and disadvantages of treatments and palliative care options.

3.2: Percentage of patients who expressed a specific wish about a medical treatment.

5: Repeated (on several occasions) formal multidisciplinary consultation with and between care providers (between settings, including GP) about care goals and palliative care option.

6: Percentage who received palliative care services ${ }^{29}$ involved in last 3 months of life.

7: Percentage who did not die in a regular hospital unit.

8: Percentage for whom the GP contacted or planned to contact the relatives regarding bereavement counselling.

\section{Statistical analyses}

Differences between countries in characteristics and quality indicator scores of those aged 65-84 years and those aged 85 years or older were analysed by using generalised linear mixed models (GLMMs) with country and potential confounders (patient characteristics that differed significantly between countries) as fixed effects and GP practice as random effect. Using GLMMs allows us to account for clustering of patient data within GP practices (possibility that one GP provided data on several patients). All analyses were completed with SPSS V.25.0.

\section{Patient characteristics}

GPs registered 3496 deaths, of which 2329 were nonsudden. The people aged $65-84$ years $(n=1126)$ were predominantly male and those aged 85 years and older $(n=1203)$ were predominantly female (table 1$)$. In both age groups, the majority did not have a diagnosis of dementia and significant differences between the countries were only found among those aged 65-84 years $(p=0.003)$. In the last year of life, between $77 \%$ in Belgium and 93\% in Spain of those aged 65-84 years resided at home $(\mathrm{p}=0.000)$, and $45 \%$ in Belgium to $88 \%$ in Italy of those aged 85 years and older resided at home $(p=0.000)$. The most common cause of death

Table 1 Patient characteristics $(n=2329)$

\begin{tabular}{|c|c|c|c|c|c|c|c|c|}
\hline \multirow{3}{*}{$\begin{array}{l}\text { Patient } \\
\text { characteristics }\end{array}$} & \multicolumn{3}{|c|}{ People aged $65-84$ years $(n=1126)$} & \multirow[b]{3}{*}{$P$ value* } & \multicolumn{3}{|c|}{ People aged 85 years and older $(n=1203)$} & \multirow[b]{3}{*}{ P value* } \\
\hline & $\begin{array}{l}\text { Belgium } \\
(\mathrm{n}=718)\end{array}$ & $\begin{array}{l}\text { Italy } \\
(\mathrm{n}=254)\end{array}$ & $\begin{array}{l}\text { Spain } \\
(n=154)\end{array}$ & & $\begin{array}{l}\text { Belgium } \\
(n=690)\end{array}$ & $\begin{array}{l}\text { Italy } \\
(\mathrm{n}=342)\end{array}$ & $\begin{array}{l}\text { Spain } \\
(\mathrm{n}=171)\end{array}$ & \\
\hline & $\mathrm{n}(\%)$ & $\mathrm{n}(\%)$ & $\mathrm{n}(\%)$ & & $\mathrm{n}(\%)$ & n $(\%)$ & $\mathrm{n}(\%)$ & \\
\hline $\begin{array}{l}\text { Mean age at death } \\
\text { (SD) }\end{array}$ & $76.7(5.7)$ & $77.7(5.3)$ & $77.3(5.5)$ & 0.080 & $90.1(4.2)$ & $90.5(4.0)$ & $90.7(4.3)$ & 0.140 \\
\hline Gender, female & $337(47.1)$ & $123(49.2)$ & $55(35.7)$ & 0.020 & $462(67.2)$ & $230(68.0)$ & $103(60.2)$ & 0.320 \\
\hline \multicolumn{9}{|l|}{ Dementia diagnosis } \\
\hline None & $467(69.5)$ & $182(72.2)$ & $130(86.1)$ & 0.003 & $328(50.2)$ & $164(48.8)$ & $87(52.1)$ & 0.799 \\
\hline Mild & $83(12.4)$ & $35(13.9)$ & $13(8.6)$ & & $136(20.8)$ & $79(23.5)$ & $39(23.4)$ & \\
\hline Severe & $122(18.2)$ & $35(13.9)$ & $8(5.3)$ & & $190(29.1)$ & $93(27.7)$ & $41(24.6)$ & \\
\hline \multicolumn{9}{|l|}{$\begin{array}{l}\text { Longest place of } \\
\text { residence in the last } \\
\text { year of life }\end{array}$} \\
\hline At home & $515(77.3)$ & $231(92.0)$ & $136(92.5)$ & 0.000 & $290(45.0)$ & $300(88.2)$ & $129(75.9)$ & 0.000 \\
\hline Care homet & $151(22.7)$ & $20(8.0)$ & $11(7.5)$ & & $354(55.0)$ & $40(11.8)$ & $41(24.1)$ & \\
\hline \multicolumn{9}{|l|}{ Main cause of death } \\
\hline Cancer & $348(51.4)$ & $121(50.2)$ & $104(68.0)$ & 0.015 & $160(24.4)$ & $53(15.6)$ & $39(22.8)$ & 0.014 \\
\hline $\begin{array}{l}\text { Cardiovascular } \\
\text { disease }\end{array}$ & $89(13.1)$ & $40(16.6)$ & $14(9.2)$ & & $172(26.2)$ & $126(37.1)$ & $45(26.3)$ & \\
\hline $\begin{array}{l}\text { Nervous system } \\
\text { disease }\end{array}$ & $75(11.1)$ & $21(8.7)$ & $7(4.6)$ & & $75(11.4)$ & $32(9.4)$ & $21(12.3)$ & \\
\hline Respiratory disease & $54(8.0)$ & $26(10.8)$ & $6(3.9)$ & & $72(11.0)$ & $43(12.6)$ & $9(5.3)$ & \\
\hline Stroke (CVA) & $39(5.8)$ & $12(5.0)$ & $3(2.0)$ & & $61(9.3)$ & $34(10.0)$ & $18(10.5)$ & \\
\hline Other & $72(10.6)$ & $21(8.7)$ & $19(12.4)$ & & $116(17.7)$ & $52(15.3)$ & $39(22.8)$ & \\
\hline
\end{tabular}

People aged 65-84 years: Missing data, $n$ (\%): gender, 6 (0.5), dementia diagnosis, 51 (4.5), longest place of residence in the last year of life, 62 (5.5), main cause of death, 55 (4.9).

People aged 85 years and older: Missing data, $n(\%)$ : gender, 7 (0.6), dementia diagnosis, 46 (3.8), longest place of residence in the last year of life, 49 (4.1), main cause of death, 36 (3.0).

*Tested for differences between countries using generalised linear mixed models to account for clustering at general practitioner level. tIncludes care/nursing homes, 'elswhere' not included in the analysis.

CVA, cerebrovascular accident; SD, standard deviation . 
in those aged $65-84$ years was cancer $(\mathrm{p}=0.015)$ and of those aged 85 years and older was cardiovascular diseases $(p=0.014)$.

\section{Quality of primary palliative care in Belgium, Italy and Spain}

Higher quality indicator scores were reported in Belgium than in Italy in both age groups (table 2). Exceptions are discussions between GPs and family of illness-related topics (aged 65-84: 76\% in Belgium vs $82 \%$ in Italy $(\mathrm{OR}=1.50,95 \% \mathrm{CI} 0.90$ to 2.49$)$; aged $85+: 81 \%$ in Belgium vs $83 \%$ in Italy $(\mathrm{OR}=1.17$, $95 \% \mathrm{CI} 0.72$ to 1.90$)$ ) and bereavement counselling (aged 65-84: 68\% in Belgium vs 68\% in Italy $(\mathrm{OR}=1.29,95 \% \mathrm{CI} 0.73$ to 2.29$)$; aged $85+: 64 \%$ in Belgium vs $69 \%$ in Italy $(\mathrm{OR}=0.93,95 \% \mathrm{CI}$ : 0.54 to 1.63)). We found a difference in discussions between GPs and patients regarding illness-related topics for more patients in Belgium than in Italy (aged 65-84: $61 \%$ in Belgium vs $20 \%$ in Italy $(\mathrm{OR}=0.12,95 \% \mathrm{CI}$ 0.07 to 0.20 ); aged $85+: 47 \%$ in Belgium vs $9 \%$ in Italy $(\mathrm{OR}=0.09,95 \% \mathrm{CI} 0.05$ to 0.16$))$. Among those aged 65-84 years, we also found a difference for the quality indicator regarding GP awareness of patient preferences about medical treatments (44\% in Belgium vs $15 \%$ in Italy $(\mathrm{OR}=0.16,95 \% \mathrm{CI} 0.10$ to 0.27$)$ ). Among those aged 85 years and older, there were differences in the quality indicators on involvement of palliative care services in the last month of life $(61 \%$ in Belgium vs $18 \%$ in Italy $(\mathrm{OR}=0.18,95 \% \mathrm{CI} 0.11$ to 0.30$)$ ) and pain measurement in the last 3 months of life (45\% in Belgium vs $15 \%$ in Italy $(\mathrm{OR}=0.20$, 95\% CI 0.11 to 0.39$)$ ).

We also identified important differences between Belgium and Spain in involvement of palliative care services in the last 3 months of life (aged 65-84: 62\% in Belgium vs 89\% in Spain (OR=4.81, 95\% CI 2.41 to 9.61 ); aged $85+: 61 \%$ in Belgium vs $77 \%$ in Spain $(\mathrm{OR}=3.1,95 \% \mathrm{CI} 1.71$ to 5.53$)$ ) (table 2). In those aged 65-84 years, we found differences for the quality indicator on GP awareness of patient preferences about medical treatments (44\% in Belgium vs $18 \%$ in Spain $(\mathrm{OR}=0.18,95 \% \mathrm{CI} 0.11$ to 0.31$)$ ) and in those aged 85 years and older on multidisciplinary consultations during the last month of life (38\% in Belgium vs $10 \%$ in Spain $(\mathrm{OR}=0.15,95 \% \mathrm{CI} 0.08$ to 0.30$))$.

\section{DISCUSSION}

In both age groups, for almost all quality indicators, higher scores were found for Belgium than Italy, and fewer consistent differences were found between Belgium and Spain. GPs in all countries reported relatively low scores on pain measurement in the last 3 months of life, discussions between GPs and patient, and multidisciplinary consultations during the last month of life. At the same time, relatively high scores were reported in all countries regarding discussions between GP and family of illness-related topics and bereavement counselling.

The three countries in the study have palliative care frameworks and strategies that specify standards and aims regarding the organisation and provision of palliative care $^{21-23}$; however, having frameworks and strategies alone is not enough to achieve high-quality palliative care. We identified that the overall quality of primary palliative care for the older population in Italy was considerably lower than in Belgium. The relatively high scores in Belgium may be explained by the well-established palliative home care teams and region-wide palliative care networks that promote collaboration and sharing of knowledge and expertise with GPs. ${ }^{30} 31$ In Italy, on the other hand, palliative home care is still mainly provided to people with cancer, ${ }^{32}$ which may contribute to lower quality indicator scores for the population included in this study. The differences between Belgium and Spain were not consistently in the same direction. In Spain, we identified relatively high-quality indicator scores on the involvement of specialised palliative care services in the last 3 months of life. In the last decade, considerable efforts have been made in Spain to expand palliative care services from patients with cancer to patients without cancer, ${ }^{33}$ with a close collaboration between GPs and palliative care services. ${ }^{33}$ The differences in the scores on the involvement of specialised palliative care services are not necessarily concerning; GPs often provide palliative care themselves. However, this needs further research as we can expect exacerbations and complex situations among an older population where specialised advice and collaboration with the GP can be highly beneficial.

In all three countries, there is room for improvement in the quality of primary palliative care for the older population. This is an urgent matter given the rising number of people who are in need of palliative care, the current ageing of populations and trends in chronic morbidity. ${ }^{1}$ We identified that pain was not regularly measured in the older population. This is concerning given that poor pain assessment has been cited as an important barrier to adequate pain control. ${ }^{35}$ Research shows that pain is an important symptom in around a third of the older population, ${ }^{45}{ }^{36}$; it is therefore crucial that frequent comprehensive pain assessment is provided. ${ }^{37}$

We found that in all countries more than half of GPs did not communicate with the patient (except for those aged 65-84 years in Belgium) regarding illness-related topics and were not aware of their preferences about medical treatments. These low scores may be influenced by the difficulty of prognosis in older people, ${ }^{38}$ something seen as an important barrier to the initiation of discussion with the patient, that is, difficulties in deciding the 'right' time to broach the topic. ${ }^{38}$ Decline in, for example, speech and cognition could also hinder communication ${ }^{39}$ and cultural factors are also 


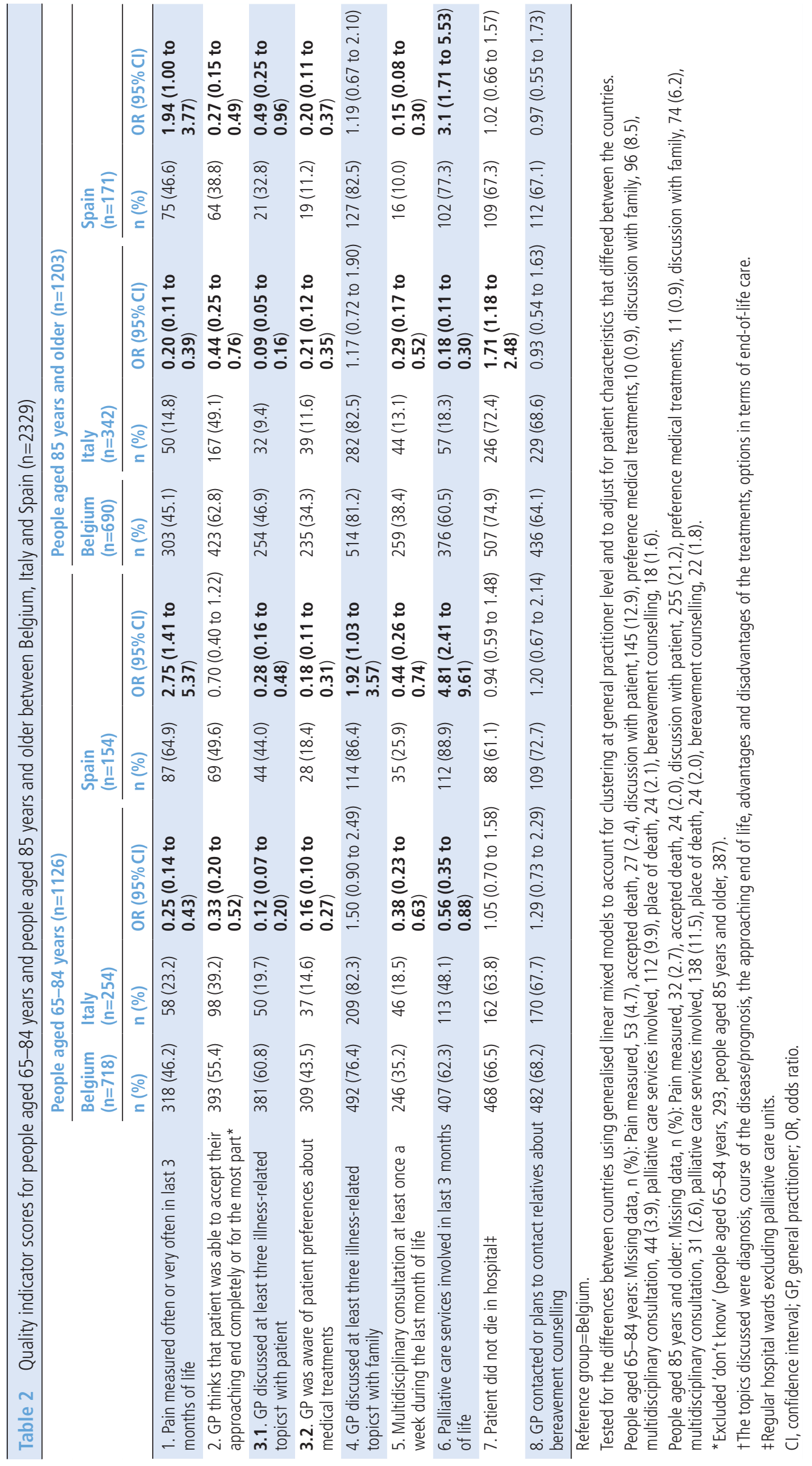


likely to influence it; in several countries, including Italy, partial or non-disclosure in advanced diseases is still common. ${ }^{24}$

GPs in all countries reported relatively high scores on communication with the family carer. As most people resided at home in the last year of life, especially in Italy and Spain, it seems that the family carer was highly involved in care and that GPs tend to communicate with them as an alternative to communicating with the patient.

The complex needs and problems of older people require joint working and interdisciplinary collaboration between different healthcare professionals. ${ }^{4}$ In our study, we identified that for most people there were no regular multidisciplinary meetings conducted in the last month of life (ie, fewer than one a week). As multidisciplinary meetings are crucial in facilitating interdisciplinary collaboration ${ }^{40}$ they should be conducted regularly. In Spain and Belgium, efforts have been made to encourage and provide guidance in facilitating interdisciplinary collaboration. ${ }^{41} 42$ The Spanish Association of Palliative Care (SECPAL) developed a model recommending multidisciplinary meetings, but does not yet provide a clear guidance on how to organise such meetings. ${ }^{41}$ The Belgian Healthcare Knowledge Centre (KCE) has developed a position paper that makes recommendations for organising these meetings in an efficient manner, such as by using a shared care plan or a shared patient medical record..$^{42}$ In addition, appointing a key person responsible for organising such multidisciplinary meetings could improve their quality. ${ }^{40}$

\section{Strengths and limitations}

To our knowledge, this is the first cross-national population-based study using a validated minimum quality indicator set to measure the quality of primary palliative care for older people. We used existing sentinel networks of GPs in the three European countries and therefore obtained samples of deaths representative for the GP population in the three countries. ${ }^{18}$ Another strength is that GPs conducted registrations weekly, limiting recall bias. ${ }^{18}$ The identification of non-sudden deaths as denominator is an advantage compared with including patients who died suddenly and unexpectedly because the patients who died non-suddenly were likely to have received palliative care. Our study also has limitations. We used only GP estimations of the care provided by themselves and not by others, so misclassifications might have occurred. Future studies should consider to also include the views of other healthcare professionals who are important providers of generalist palliative care, such as district and community nurses.

\section{CONCLUSION}

This study found that there are considerable crosscountry differences in the quality of primary palliative care for older people, probably reflecting different healthcare systems and cultures. Our findings show that the overall quality of primary palliative care for older people could be improved. Initiatives are needed to support regular pain measurement, communication between GP and patient and frequent multidisciplinary meetings in the last month of life. These focal points should become a priority for policy-makers and healthcare professionals, given the rising number of older people in need of palliative care.

Twitter Kim de Nooijer@KimNooijer

Acknowledgements The authors would like to thank all participating general practitioners of the Sentinel Networks for providing the data for this study and Jane Ruthven for linguistic help.

Contributors LD, GM, TVA and LVdB designed the study. $\mathrm{LVdB}, \mathrm{LD}$ and LP contributed to the construction of quality indicators. SM, GM and TVA monitored data collection. KdN and LP analysed the data. All authors contributed to data interpretation. KdN drafted the article. All authors critically reviewed the article and gave final approval of the version to be published.

Funding This work was supported by the Research Foundation - Flanders (under grant agreement G.0303.16) and by the AXA Research Fund (Postdoctoral Fellowship to LP). LP is a Postdoctoral Fellow of the Research Foundation - Flanders (no grant number).

\section{Competing interests None declared.}

\section{Patient consent for publication Not required.}

Ethics approval In Belgium, the study protocol was approved by the Ethical Review Board of Brussels University Hospital of the Vrije Universiteit Brussel. In Italy, the ethical approval for data collection was obtained from the Local Ethical Committee Comitato Etico della Azienda Sanitaria Firenze, Tuscany. No ethics approval was required in Spain.

Provenance and peer review Not commissioned; externally peer reviewed.

Data availability statement Data are available on reasonable request.

Open access This is an open access article distributed in accordance with the Creative Commons Attribution Non Commercial (CC BY-NC 4.0) license, which permits others to distribute, remix, adapt, build upon this work noncommercially, and license their derivative works on different terms, provided the original work is properly cited, appropriate credit is given, any changes made indicated, and the use is noncommercial. See: http://creativecommons.org/licenses/by-nc/4. $0 /$.

ORCID iD

Kim de Nooijer http://orcid.org/0000-0003-2887-6832

\section{REFERENCES}

1 Albers G, Martins Pereira S, Onwuteaka-Philipsen B. A public health perspective on palliative care for older people: an introduction. In: Palliative care for older people : a public health perspective. Oxford, UK: Oxford University Press, 2015: 3-16.

2 World Health Organization. Strengthening of palliative care as a component of integrated treatment throughout the life course, 2013. Available: http://apps.who.int/gb/ebwha/pdf_ files/EB134/B134_28-en.pdf

3 Marengoni A, Angleman S, Melis R, et al. Aging with multimorbidity: a systematic review of the literature. Ageing Res Rev 2011;10:430-9. 
4 Hall S, Petkova H, Tsouros AD, et al. Palliative care for older people: better practices. World Health Organization, 2011.

5 World Health Organization. Who definition of palliative care, 2014. Available: https://www.who.int/cancer/palliative/ definition/en/

6 Bone AE, Gomes B, Etkind SN, et al. What is the impact of population ageing on the future provision of end-of-life care? population-based projections of place of death. Palliat Med 2018;32:329-36.

7 Gomes B, Calanzani N, Gysels M, et al. Heterogeneity and changes in preferences for dying at home: a systematic review. BMC Palliat Care 2013;12:7.

8 Goodman C, Evans C, Wilcock J, et al. End of life care for community dwelling older people with dementia: an integrated review. Int J Geriatr Psychiatry 2010;25:329-37.

9 Van den Block L. The need for integrating palliative care in ageing and dementia policies. The European Journal of Public Health 2014;24:705-6.

10 Dixon D, King D, Matosevic T, et al. Equity in the provision of palliative care in the UK: review of evidence. London, UK: London School of Economics and Political Science, Personal Social Services Research Unit, 2015.

11 Miesfeldt S, Murray K, Lucas L, et al. Association of age, gender, and race with intensity of end-of-life care for Medicare beneficiaries with cancer. J Palliat Med 2012;15:548-54.

12 Rolls L, Seymour JE, Froggatt KA, et al. Older people living alone at the end of life in the UK: research and policy challenges. Palliat Med 2011;25:650-7.

13 Johnson MJ, Bland JM, Gahbauer EA, et al. Breathlessness in elderly adults during the last year of life sufficient to restrict activity: prevalence, pattern, and associated factors. $J \mathrm{Am}$ Geriatr Soc 2016;64:73-80.

14 Lindskog M, Tavelin B, Lundström S. Old age as risk indicator for poor end-of-life care quality - a population-based study of cancer deaths from the Swedish register of palliative care. Eur J Cancer 2015;51:1331-9.

15 Miranda R, Penders YWH, Smets T, et al. Quality of primary palliative care for older people with mild and severe dementia: an international mortality follow-back study using quality indicators. Age Ageing 2018;47:824-33.

16 Bainbridge $\mathrm{D}$, Seow $\mathrm{H}$. Measuring the quality of palliative care at end of life: an overview of data sources. Healthy Aging Clin Care Elder 2016;8:9-15.

17 Rosenfeld K, Wenger NS. Measuring QUALITYIN end-of-life care. Clin Geriatr Med 2000;16:387-400.

18 Van den Block L, Onwuteaka-Philipsen B, Meeussen K, et al. Nationwide continuous monitoring of end-of-life care via representative networks of general practitioners in Europe. BMC Fam Pract 2013;14:73.

19 Singer PA, Martin DK, Bowman K. Quality end-of-life care: where do we go from here? J Palliat Med 2000;3:403-5.

20 Grunfeld E, Lethbridge L, Dewar R, et al. Towards using administrative databases to measure populationbased indicators of quality of end-of-life care: testing the methodology. Palliat Med 2006;20:769-77.

21 Groeneveld EI, Cassel JB, Bausewein C, et al. Funding models in palliative care: lessons from international experience. Palliat Med 2017;31:296-305.

22 Lynch T, Centeno C, Donea O, et al. Eapc atlas of palliative care in Europe. EAPC Press, 2013.

23 Kringos DS, Boerma WGW, Hutchinson A, et al. Building primary care in a changing Europe. Copenhagen, Denmark: European Observatory on Health Systems and policies, 2015.

24 Gysels M, Evans N, Meñaca A, et al. Culture and end of life care: a scoping exercise in seven European countries. PLoS One 2012;7:e34188.
25 van der Heide A, Deliens L, Faisst K, et al. End-Of-Life decision-making in six European countries: descriptive study. The Lancet 2003;362:345-50.

26 Borgsteede SD, Deliens L, Francke AL, et al. Defining the patient population: one of the problems for palliative care research. Palliat Med 2006;20:63-8.

27 Leemans K, Deliens L, Francke AL, et al. Quality indicators for palliative care services: Mixed-method study testing for face validity, feasibility, discriminative power and usefulness. Palliat Med 2015;29:71-82.

28 Penders YWH, Onwuteaka-Philipsen B, Moreels S, et al. Differences in primary palliative care between people with organ failure and people with cancer: an international mortality follow-back study using quality indicators. Palliat Med 2018;32:1498-508.

29 Pivodic L, Pardon K, Van den Block L, et al. Palliative care service use in four European countries: a cross-national retrospective study via representative networks of general practitioners. PLoS One 2013;8:e84440.

30 Van Beek K, Woitha K, Ahmed N, et al. Comparison of legislation, regulations and national health strategies for palliative care in seven European countries (results from the Europall Research group): a descriptive study. BMC Health Serv Res 2013;13:275.

31 Pype P, Peersman W, Wens J, et al. What, how and from whom do health care professionals learn during collaboration in palliative home care: a cross-sectional study in primary palliative care. BMC Health Serv Res 2014;14:501.

32 Scaccabarozzi G, Lovaglio PG, Limonta F, et al. Quality assessment of palliative home care in Italy. J Eval Clin Pract 2017;23:725-33.

33 Ministry of Health, Social Services And Equality. Palliative Care Strategy of the National Health System. 2010 2014 Update, 2012. Available: http://www.mscbs.gob.es/ organizacion/sns/planCalidadSNS/docs/paliativos/PalliativeCa reStrategySpanishHS.pdf

34 Centeno C, Carrasco JM, Woitha K, et al. Policies on palliative care for older people in Europe. In: Palliative care for older people : a public health perspective. Oxford, UK: Oxford University Press, 2015.

35 Schofield P, Abdulla A. Pain assessment in the older population: what the literature says. Age Ageing 2018;47:324-7.

36 Ags panel on persistent pain in older persons. the management of persistent pain in older persons. J Am Geriatr Soc 2002;50:S205-24.

37 Herr KA, Garand L. Assessment and measurement of pain in older adults. Clin Geriatr Med 2001;17:457-78.

38 Pollock K, Seymour J. Communication and advance care planning for older people. In: Palliative care for older people : a public health perspective. Oxford, UK: Oxford University Press, 2015: 236-48.

39 Abarshi E, Echteld MA, Van den Block L, et al. The oldest old and GP end-of-life care in the Dutch community: a nationwide study. Age Ageing 2010;39:716-22.

40 Piers R, Van Den Noortgate N, Vyt A. Collaboration between professionals as a necessary condition for palliative care. In: Palliative care for older people : a public health perspective. Oxford, UK: Oxford University Press, 2015: 226-35.

41 Gomez-Batiste X, Ferris F. Ensure good quality palliative care. A Spanish Model. European Journal of Palliative Care 2008;15.

42 Paulus D, Van den Heede K, Mertens R. Position paper: organisation of care for chronic patients in Belgium. health services research (hsr. Brussels: Belgian Health Care Knowledge Centre (KCE), 2012. 